Conference Proceedings

Journal of Technology in Counselor Education and Supervision (ISSN 2692-4192)

Volume 1(1): 53 - 56

(C) 2021Journal of Technology in Counselor Educationand Supervision

https://doi.org/10.22371/tces/0010

\title{
Effective Online Synchronous Group Counselor Training: Challenges, Strengths, and Solutions
}

\author{
Cristen C. Wathen ${ }^{1}$, Megan Speciale ${ }^{2}$, Szu-Yu Chen ${ }^{3}$, \& Donna Sheperis ${ }^{4}$
}

\begin{abstract}
This paper on Online Synchronous Group Counselor training was presented at the first annual Counselor Education Distance Learning Conference on February 19, 2021. In the Counseling field, skills-based courses like Group Counseling are often taught in residential settings regardless of whether the training program is online or brick and mortar. With the Covid 19 pandemic, all courses had to be moved online almost overnight. Describing a model for teaching Group Counseling in an online virtual synchronous format, this article shares strategies, opportunities, and challenges for group instructors in counselor training programs during the Covid 19 pandemic and beyond.
\end{abstract}

\section{Keywords}

group counseling, synchronous, distance learning

Alongside numerous pedagogies specific to the online format, the Association for Counselor Education and Supervision (ACES) has endorsed its own guidelines for online learning (ACES, 2017), showing its support of this method of counselor training. Additionally, to date, the Council for Accreditation of Counseling and Related Educational Programs (CACREP) has accredited a number of fully online counselor education programs, supporting the ability to provide quality counselor training with an absence of in person contact between faculty and students. Despite this support, scholarly research in counselor education around best practices and effectiveness has not substantially increased. Barrio-Minton (2019) reported that in a thematic analysis of counselor education and supervision articles published in 2017 , only $4 \%$ were pertaining to distance counselor education. As the transition to online learning was suddenly forced by the COVID-19 pandemic (Christian et al., 2020), distance education initially became the norm for most counselor education programs. This shift has meant that many skills-based courses, like Group Counseling, are being taught through technology platforms that many educators and students were previously unfamiliar with.

\footnotetext{
1 Palo Alto University, Palo Alto, CA, USA

2 Palo Alto University, Palo Alto, CA, USA

3 Palo Alto University, Palo Alto, CA, USA

4 Palo Alto University, Palo Alto, CA, USA
}

Group counseling is a class that presents unique opportunities, concerns, and challenges for counselor education programs using an online synchronous training model and for programs that moved online due to the COVID-19 pandemic. This paper discusses these aspects of teaching group counseling in this modality and offers ideas and solutions for group counseling instructors.

CACREP (2015) identified group counseling as one of the eight core content areas required for all graduates of accredited counseling and related educational programs. Attending to learning outcomes, CACREP also requires 10-clock-hours of direct group experience, where students participate in group through a program-approved small group activity (CACREP, 2015). This experiential component provides essential training for clinical skills; however, there is a paucity of research describing educational best practices in synchronous online learning environments about group counseling and/or the small group experience (Chen et al. 2020). Common strategies to address this requirement include professionally facilitated in-class groups, instructor-facilitated in-class groups, peerfacilitated in-class groups, and requiring students to

Corresponding Author: Cristen Wathen, $\mathrm{PhD}$, Palo Alto University, 1791 Arastradero Road, Palo Alto, CA 94304 email: cwathen@paloaltou.edu 
obtain external group counseling (cf. Shumaker et al., 2011). The following is an example structure of an online Group Counseling course utilizing peer-facilitated in-class groups.

\section{Peer-Facilitated Online Process Groups: Structure and Strategy}

This online group counseling class format is designed for a master's only program operating on a quarter system, though it is easily adapted for semester settings. The class meets for a total of two hours, with 30 minutes of large group lecture and discussion, one hour of the small group experience, and then 30 minutes of final processing and reflection with the instructor, again in a large group setting.

In this peer facilitated model, master's students are divided up into small groups of five to seven students, making up the experiential small groups, and each group meets in a videoconference breakout room weekly during the class session. Weekly readings and videos on group counseling topics are provided asynchronously. In class, instructors discuss the reading materials and demonstrate skills before moving students to the synchronous experiential groups. Instructors assign two students to lead the groups each week and these group leaders are responsible for determining their approach, activities, for working together to create a group plan, and for working with instructors to have the plan approved.

Throughout the quarter, instructors may incorporate a reflecting team with two members of the group observing the live session with their video and microphones off. This reflecting team can note the displayed group counseling skills observed, look for group process information, and give feedback to the group after the session ends. During the small group sessions, instructors and teaching assistants move back and forth among the groups, providing specific in-vivo feedback to the group leaders to help them progress and develop their group counseling skills. With direct messaging, instructors can give this private feedback immediately to the group leaders without other members of the group seeing the instructor's suggestions. Weekly journals are required for each member of the class. This journal reflection includes writing a group session note and integrating the class readings with their actual experience in the small group session.

\section{Ethical Considerations of Online Process Groups}

When instructors run the course as group leaders, they can be perceived as being both the educator and the group counselor, potentially causing role confusion and a challenging power dynamic for students. Requiring group experiences outside of class costs students extra time and potentially expense and could be more challenging to find during the COVID-19 pandemic. The recognition of these ethical dilemmas supported our decision to use the peer facilitation model for our in class online groups. In this model, dual relationships among students are unavoidable. To mitigate potential negative effects, instructors must clearly define the scope and intention of the in-class group (Chen et al., 2020). Namely, it should be clear that the groups are not intended to be a personal therapy group and, rather, are framed as professional development groups aimed toward processing issues related to counselor training. Students are instructed to exercise discretion regarding the nature of their personal disclosure and are reminded that the group experience is an experiential portion of the course, and not a therapy group. Noted in the syllabus and emphasized in class, students are informed that their disclosure in the small groups is not related to their course grade, rather their grade is based on group attendance and completion of the required assignments in the class.

In this type of classroom setting, instructors and students are likely to face ethical dilemmas unique to the use of videoconference in group skills training. For example, it is common in online groups for members to initially feel distracted by the videoconference platform, as they are able to see themselves and are aware that others are also seeing them and also potentially seeing inside their homes. Kozlowski and Holmes (2014) found that this "hyperawareness" of the online environment often initiated perceptions of artificiality about the group, high levels of scrutiny about one's self-representation, and feelings of distrust about other members' level of commitment to the group. Because conversational turn-taking and flow can often feel less natural over videoconference (especially to new and less tech-savvy users), the group can struggle to get to a deeper, more cohesive working dynamic. Instructors can guide student facilitators to introduce centering activities at the beginning of group sessions and to work with the group to set rules about how it wants to use the microphone and muting technologies.

Online groups also possess unique considerations related to confidentiality. Throughout the COVID-19 pandemic, many students have experienced major changes to their living and working spaces, especially for students that are cohabitating with others and students with parenting or caregiving responsibilities. Students may struggle to access to private, noise-reduced space and may have to join class from closets, cars, or outdoors, for example. Even with the use of headphones, group members may feel less safe sharing openly when other members seem distracted or when 
video backgrounds do not appear private. It is imperative for the group to establish reasonable and attainable boundaries regarding setting, privacy, video backgrounds, and other possible distractions early in the group forming process and throughout the duration of the group (Chen et al., 2020). Additionally, the group norm discussions may be used to process members' thoughts and feelings related to other issues related to videoconference (i.e., technology disruptions) to normalize possible frustration and collaboratively strategize ways to facilitate cohesions despite these realities.

\section{Strengths and Challenges to a Synchronous Model of Group Training}

When compared to in-person groups, videoconference groups may face additional barriers to trust and cohesion (Holmes \& Kozlowski, 2015). Yet, online synchronous group counseling skills development offers a unique learning possibility. Specific to the numerous changes ushered by the COVID-19 pandemic, online group facilitation provides an important and timely learning opportunity as clinical mental health counseling agencies nationwide have rapidly transitioned to telehealth services. Through in-class experiential groups, students are able to receive in vivo supervision of their online group facilitation, while tackling issues that are specific to online settings, such as dealing with technological difficulties, maintaining confidentiality in shared living spaces, and managing flow and participation over videoconference. Given that the trend of telehealth services has increased throughout the duration of the pandemic and beyond, it is imperative that students are given opportunities to practice clinical skills in both face-to-face and online settings.

An additional benefit to online process groups is the ability for students to track in real time when and how they physically respond to group stimuli. Nonverbal cues, such as facial expressions, body language, and eye contact may be easily observed through the forward-facing webcam, which can be especially helpful for recognizing internal reactions or countertransference to specific topics, interactions, or group disruptions. Instructors may use this opportunity both in live sessions and in session recordings (which are easier to record in online platforms) to provide feedback to students regarding their nonverbal behaviors and invite discussion on how these responses may impact group cohesion and engagement.

There are also noted challenges in teaching group counseling remotely. Technological difficulties, such as screen freezes, delays in back-and-forth communication, and loss of connection can impact the group process. Including technology resolutions in the informed consent and early stages of a group can normalize the frustration and confusion when these circumstances inevitably occur. It is important for instructors to have an alternative plan in place so that students feel comfortable and supported when technology disrupts the group process. Another challenge is the use of private chat. Students could potentially engage in private conversations through direct messaging or texting, while other group members are unaware. At times this could be helpful if a student needs support; however, it is problematic in regard to group trust and rapport. Clear communication around boundaries and expectations are important from the first class session on. Additional challenges we have experienced are peer facilitators' utilization of handouts and activities in group sessions. For certain activities, group members may need information about what to have for the class group session ahead of class time or handouts need to be sent in advance. It is important for group peer facilitators to think through their group plan and be proactive about the activities and handouts that they want to include in their synchronous group experience.

\section{Conclusion}

The COVID-19 pandemic has impacted the pedagogy of counselor education in unprecedented and unexpected ways. In the past, the transition of skills-based classes like group counseling to an online setting has been slowly and thoughtfully implemented by counselor educators. Currently, many programs have had no other alternatives. The online synchronous group counseling course model presented can be successfully delivered remotely in a way that promotes robust learning outcomes and a positive clinical training experience during the COVID-19 pandemic and in a postCOVID world.

\section{References}

Association of Counselor Education and Supervision Technology Interest Network. (2017). ACES guidelines for online learning in counselor education. https://acesonline.net/knowledge-base/ aces-guidelines-for-onlinelearning-2017-2

Barrio-Minton, C. A. (2019). Counselor Education and Supervision: 2017 inaugural review. Counselor Education and Supervision, 58(1), 4-17. https://doi.org/10.1002/ ceas. 12120

Council for Accreditation of Counseling and Related Educational Programs. (2015). 2016 CACREP standards. http:// www.cacrep.org/wp-content/uploads/2017/08/2016-Standards-with-citations.pdf

Chen, S. Y., Wathen, C., \& Speciale, M. (2020). Online clinical training in the virtual remote environment: Challenges, opportunities, and solutions. The Professional Counselor, 10(1), 78-91. https://eric.ed.gov/?id=EJ1250982 
Christian, D. D., McCarty, D. L., \& Brown, C. L. (2020). Experiential education during the COVID-19 pandemic: A reflective process. Journal of Constructivist Psychology, 1-14. https://doi.org/10.1080/10720537.2020.1813666

Holmes, C. M., \& Kozlowski, K. A. (2015). A preliminary comparison of online and face-to-face process groups. Journal of Technology in Human Services, 33(3), 241-262. https://doi.org/10.1080/15228835.2015.1038376

Kozlowski, K. A., \& Holmes, C. M. (2014). Experiences in online process groups: A qualitative study. The Journal for Specialists in Group Work, 39(4), 276-300. https://doi. org/10.1080/01933922.2014.948235

Shumaker, D., Ortiz, C., \& Brenninkmeyer, L. (2011). Revisiting experiential group training in counselor education: $A$ survey of master's-level programs. The Journal for Specialists in Group Work, 36(2), 111-128. https://doi.org/1 $0.1080 / 01933922.2011 .562742$ 